\title{
Development of an Enterprise Architecture for Healthcare using TOGAF ADM
}

\author{
Abba Suganda Girsang ${ }^{1 *}$, Achmad Abimanyu ${ }^{1}$ \\ ${ }^{1}$ Computer Science Department, BINUS Graduate Program - Master of Computer Science, Bina Nusantara University, Jakarta, 11480 Indonesia
}

\begin{abstract}
Hospital is one of the most complex organization with highly intensive interaction between stakeholders (patients, nurses, doctors, staff, etc.). In the operation of a hospital, the use of Information technology has been proven to improve effectiveness and efficiency. However, in the majority of cases, the processes to achieve the Strategic Objectives through implementation of Information Technology are full of challenges. Based on the case study in Dharmais Cancer Hospital, there are many symptoms that are identified by this study and lead to 4 issues, namely: lack of ownership from Business users, lack of alignment between business strategy and IT strategy, lack of awareness to use IT as a tool for competitive advantage, and low quality of IT operation performances. In order to solve the issues and support the achievement of Strategic Business Objective through IT, an Enterprise Architecture approach can be used to develop baseline architecture, identify the target architecture, finding the gap, and use the gap as recommendation to solve those issues. The methodology chosen is TOGAF ADM, based on its focus on processes and its flexibility to combine artifacts and approaches that are most suitable for the case. This study develops 7 recommendations to Strengthen Business area of organization, 5 recommendations to Align IT plan with Business Strategy, 16 recommendations to Implement several IT solutions as Competitive Advantage for organization, and 8 recommendations to provide higher performances by enabling Service Management approach for IT Operation. This study also shows how TOGAF ADM can improve the awareness of the business users to the business itself.
\end{abstract}

\section{Keywords:}

Architecture Governance;

Business Strategy;

Enterprise Architecture;

Hospital;

IT Strategy;

TOGAF ADM.

Article History:

Received: 25 February 2021

Revised: 11 May 2021

Accepted: 18 May 2021

Published: 01 June 2021

\section{1- Introduction}

Hospital is one of the most complex organization with highly intensive interaction between stakeholders from patients, nurses, doctors, administration staffs, and others [1,2]. In order to support the operation, the use of Information technology have proven to be able to improve effectiveness and efficiency [3, 4]. However, in majority of the cases, the process to implement the support of Information Technology has always been painful and full of challenges [5, 6]. Along the years, Dharmais Cancer Hospital in Jakarta - Indonesia, ("Dharmais") has implemented several Information Technology solutions, but the experiences from decision until implementation were not satisfactory. One of the key factors that is consistently perceived as the root cause for the not-so-smooth process of implementing Information Technology is the absence of an Enterprise Architecture as "Reference" in the Organization. This Architecture is expected to be the reference in the implementation of Information Technology, providing guidance in the execution, and used as final evaluating tool for the result [4, 7-10]. Thus, for a Hospital which experiences many problems in implementing Information Technology support, this paper sees how those problems could be avoided, mitigated, or even solved by developing an Enterprise Architecture from the current existing Business Strategy. This study also expects to

* CONTACT: Agirsang@binus.edu

DOI: http://dx.doi.org/10.28991/esj-2021-01278

(C) 2021 by the authors. Licensee ESJ, Italy. This is an open access article under the terms and conditions of the Creative Commons Attribution (CC-BY) license (https://creativecommons.org/licenses/by/4.0/). 
generate long term benefit for Dharmais, by proposing structures, mechanism, processes, and arrangement of authority for the Governance of implementation of Information Technology to support the achievement of Business Strategy [11].

Dharmais has already developed its business strategies and cascading it through the organization using Balance Score Card [12], thus what is needed further is a framework with strong emphasize on process to help "operationalize" the business strategy into a well-defined Architecture (for Information Technology implementation). This is the reason to choose Architecture Development Method (ADM) from TOGAF (The Open Group Architecture Framework). TOGAF ADM can help to detail the processes [13] and focus on Operational activity [14]. TOGAF ADM methodology provides steps to capture "as-is" status and then to develop the "target" architecture. This target architecture is a roadmap for organization to achieve its strategic objectives. TOGAF ADM, not only providing the roadmap, is also showing the gap betweeen the target with current existing condition.

Several researches have shown the benefit of TOGAF ADM in supporting Hospital or other Organization. It has the capabilities to support in Strategic Planning Process [9], to develop a Hospital Information System [15], to integrate several independent Hospital (and its related Hospital Information System) into 1 single Architecture [16] to optimize the use of IT to support the achievement of Business Objectives [17], to develop a Medical Record service [5], to improve quality of a specific service in organization [18] while also to optimize the use of existing IT platform [19], to improve implementation and creation of SOP in organization [7], and also to help in converting manual process into automation [8].

\section{2- Related Works}

\section{2-1-Implementation of TOGAF ADM to Improve Business Process and/or Increase Automatization}

In a case study in Ministry of Internal Affair, TOGAF ADM methodology is implemented to develop Standard Operating Procedures (SOP) for PUSDATIN (Centre of Data and Information). The identified problems to be solved are: Absence of SOP to support each work unit in the process of Regular Reporting, Updating and Submission of information, Absence of Storage Database, Silo approach in Application Development, and Frequent Discontinuation of Application use within the organization [7]. This study provides action plan and timeline as the result of Gap Analysis between Current and Target Architecture. However, it is not providing proposed governance of the architecture development, and implementation.

TOGAF ADM has also been used to increase the level of automatization in a company's Business Processes [8]. Moreover, this study is using the same framework to integrate scattered applications and increase the level of sharing. The result of this study is a very structured approach in the process of developing the Architecture, but it is still lacking of proposal for a formal structure that owns the Governance authority to guide the implementation of the proposed Architecture.

Another study is using TOGAF ADM to optimize current ERP Platform of a company, and integrate with other application within the company [19]. Thus, this could help to increase the service quality of IT function to internal users. This study results in a Blueprint of IT which was expected to sustain the growth of business. The TOGAF methodology is used to develop all architectural domain, then move to delivery of Opportunity and Solution, but it leaves the migration and governance plan to the company and leave it out from the study. This study has developed comprehensive steps to use primary data from stakeholders, and using it to get the approval of a proposed Architecture.

\section{2-2-Implementation of TOGAF ADM for Strategic Planning}

The use of TOGAF during Strategic Planning process was conducted in Ministry of Agriculture for Information and Technology [9]. The framework is used to identify main processes within the Ministry, and rearranging the most impactful processes that need to be prioritized based on limited Budget available. This study, though, have not aligned the separate architecture output of Business, Information and Technology. It does mention several new technologies to be accommodated (Big Data, IoT, etc.) but not providing plan to implement those technology. This may stem from the absence of "pain points" in the start of the methodology.

Another use of TOGAF ADM for Strategic Planning have been shown in order to formulate a Contingency Plan for Disaster in National Centre of Archives [17]. This study delivers comprehensive processes for management and governance for any disaster, but still lacking on the development of Technology Architecture to support the expected processes. This study is not providing clear path to reduce dependency of the organization to $3^{\text {rd }}$ party provider for technology solution.

\section{2-3-Implementation of TOGAF ADM for New Services Development or Business Consolidation}

TOGAF has also been used in combination with other tools to support improvement of Hospital Operation. One of them is a proposal to combine 3 methods, namely, BTEP (business transformation enablement program) - TOGAF ADM - ESIA (Eliminate, Simplify, Integrate, and Automate) to help consolidating Hospital operation which consisted of several branches. However, the methodology is not elaborating more on the migration, change management, and governance of the implementation of target architecture [15]. 
The proposed methodology above is put in a case study in a merged hospitals which are consisted of multiple branches [16]. The study proposes a comprehensive architecture to support the consolidation, including finding the potential upside of the consolidated processes. But, just as shown earlier, it has not provided further analysis on how the governance of an architecture is handled in the organization during the development, changes, or implementation of the architecture's element.

TOGAF ADM is also used in developing Electronic Medical Record in Hospital [5]. The approach is not using the development of as-is Architecture, but, direct to the development of Target Architecture. This study puts strong emphasize on the validation (and feedback) from stakeholders (Enterprise Architecture Design Validation). But, again, this study has not explored elements of migration plan and management of the migration (Architecture Governance and Change Management).

From all above researches, multiple variations exist in the use of TOGAF ADM to support the development of Enterprise Architecture [20]. Each variation is depending on the objectives, which could be derived from the "pain points" of each case. But, there is a consistent gap identified, which is the study of Architecture Governance and Change management in an organization, related to EA development, implementation and evaluation. This gap is highly significant since it is highly related to elements of successful use of EA which are Executive Sponsorship and User Involvement [21]. This study puts more focus on this Architecture Governance area.

\section{3- Research Framework}

The research uses the sequence as shown in Figure 1. It has 5 main stages, and stage 3 is consisted of several phases of TOGAF ADM.

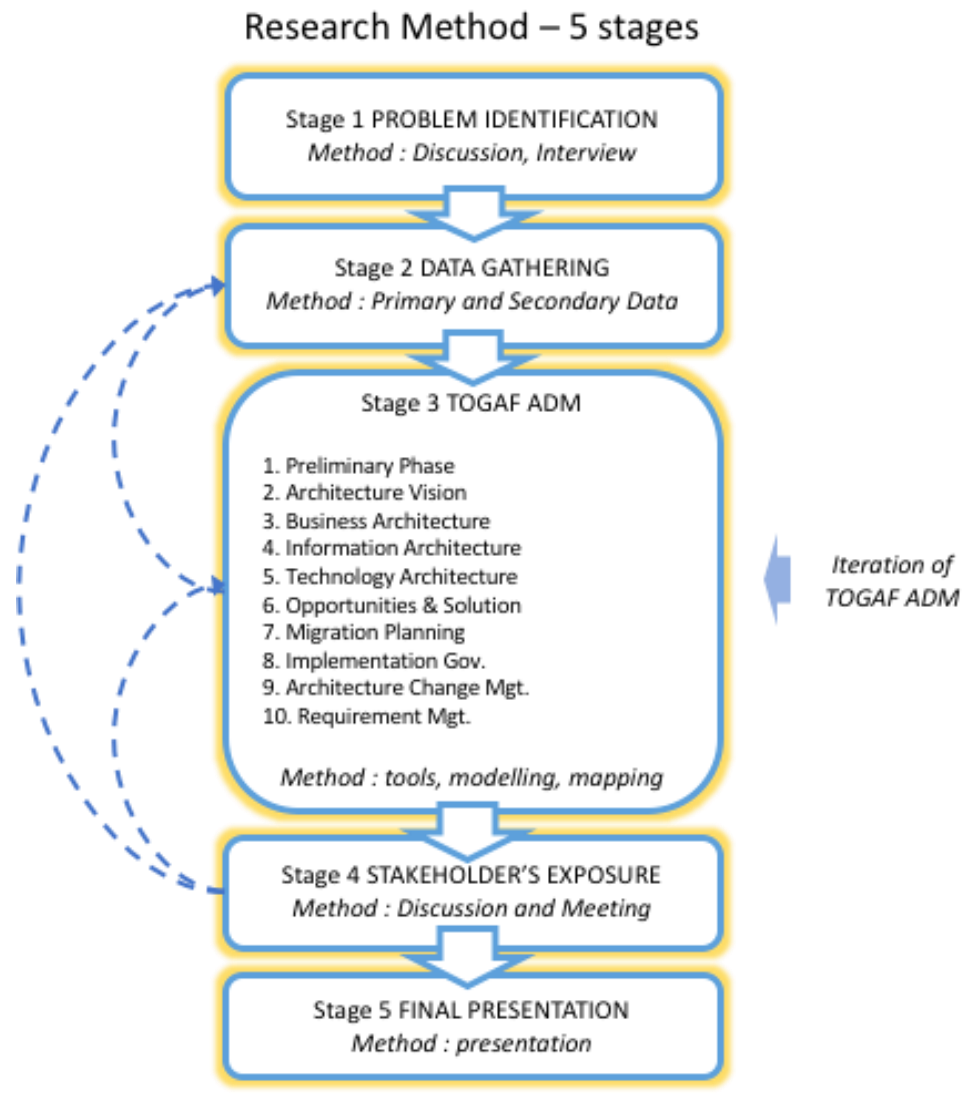

Figure 1. Research Framework.

\section{Stage 1. Problem Identification}

Identification of Problem are conducted through several steps of discussions and interviews with 3 major stakeholders from the Dharmais: Executive / Management layer, Users, and IT Department Coordinator.

\section{Stage 2. Data / Information Gathering}

Data gathering use several sources: Primary data from interviews, discussions, and Secondary data from report, regulation, benchmarking studies, etc. All this data is used to validate the final identification of problem, and for the further iteration of architecture development on the next stage. 


\section{Stage 3. TOGAF ADM Iteration}

This stage is the main processes to the study. All the phases, will be adjusted accordingly to align with current condition of Dharmais. During this stage, an iteration to gather additional data from previous stage is possible. In between phases, a Requirements Catalogue is provided throughout the phases to sustain the cycle, to identify the architecture requirements, and to ensure that requirements are available before a certain phase is executed [22].

Preliminary Phase. Activities during Preliminary phase is providing all the information necessary to start the process, such as resources allocation (people, time, rule of engagement), information on Business Strategy, and initial discussion with stakeholder. Moreover, this phase will define the architectural principles and the governance mechanism to manage full cycle of Architecture processes within the organization.

Architecture Vision. This phase identifies organization Vision, Mission, Business Model and Strategy, Value Chain diagram, and Stakeholder map matrix. A solution concept diagram will also be defined during this phase.

Business Architecture Phase. This phase identifies how the organization is structuring itself to manage the operation. It is also related to allocation, delegation, and arrangement of authority on each function, unit, or actors in the organization. Moreover, this phase will also identify Business Processes that capture the interaction between units and functions to achieve the Values defined in the Value chain.

Information Architecture Phase (Data Architecture). This phase is divided into 2 part: Data Architecture phase and Application Architecture phase. This study is putting significant focus on how the Data Management in Dharmais with understanding that Data is the key resources in Hospital that define the strategic relevance and sustainability for the organization $[3,15]$.

Information Architecture Phase (Application Architecture). This phase provides steps to capture the current application Portfolio in Dharmais. With earlier understanding of the Business Architecture and Data Architecture, this study proposes how the Target Architecture of Applications in Dharmais in alignment with Business Strategies and Objectives.

Technology Architecture Phase. This phase generates information that explain how technologies are utilized in Dharmais. Technology Portolio Catalogue and Network Diagram are developed to capture existing Architecture.

Opportunity and Solution Phase. This Phase is related to summarization of all results of the gap analysis resulted from previous phases.

Migration Planning Phase. This phase is detailing the implementation plan of Target Architecture and further subdivided the plan into several programs or projects with associated resources and capabilities requirement. This phase is not discussed, and it is not within the scope of this study.

Implementation Governance and Change Management Phase. Implementation Governance Phase provide control of the deliverables of programs/ projects, including the decision framework within Dharmais organization for solution and implementation of architecture. Change Management phase focuses on how the organization detects and responds to requirement of changes in the architecture and/or its implementation plan.

\section{Stage 4. Exposure and Decision}

Each deliverables of phases of TOGAF ADM is summarized and presented to Stakeholders of Dharmais, and possible iteration to previous stage(s) is still be possible to conclude as holistic as possible before continuing to next phase of TOGAF ADM.

\section{Stage 5. Final Presentation}

Only when all the iterations are completed for each of phases, then the study move to final conclusion of the Enterprise Architecture that are presented on the final stage. The result of this final stage are the deliverables of this study, joined with all the supporting materials that come with it.

\section{4- Results and Discussions}

\section{4-1-Preliminary Phase}

\section{4-1-1-Architecture Principles}

This study collects perspectives and requirement from several key stakeholders, which are President Director, Director of Planning, and also Head of IT installation. There are 3 key requirements developed from this interview: EA is expected to be the roadmap for maximizing IT to support achievement of objective, EA is also expected to define the "Smart" vision of the hospital, and EA recommendations should be included in near term with the plan of new building in 2023. Further, this study generates 14 architecture principles that are approved to be used during the process of EA development. Those principles are below: 
- Business Principles: 1. Information Management is Everybody's business, 2. Tasks are Designed around outcome, 3. Business Requirement-based Change, 4. Business Continuity, 5. Compliance with Law;

- Data Principles: 6. Data is an Asset, 7. Data Security, 8. Data is Shared, 9. Data is Accessible, 10. Data trustee;

- Application Principles: 11. IT system are Standardized and Reused, 12. Interoperability;

- Technology Principles: 13. IT System support 24*7 availability, 14. Technology Independent.

\section{4-1-2-Architecture Governance}

Since the success of an Information System project is seen as having great dependencies on how the governance is setup, then this study is reviewing how the governance scheme available in Dharmais to support EA development and maintenance. Governance is achieved by applying measure on several levels of organizations, namely, Strategic, Business, and Operational levels [23]. This study finds out that there has not been any function and unit with capabilities to provide management of Architecture governance in Dharmais. To continue with the process, an adjusted governance scheme is developed by this study, based on Architecture Governance scheme in TOGAF, and completed with further research through several documents in Dharmais. The result is shown in Figure 2. This scheme has identified the existence of a "Quality Committee" in Hospital organization with a role that match with the requirement of the reference scheme by TOGAF.

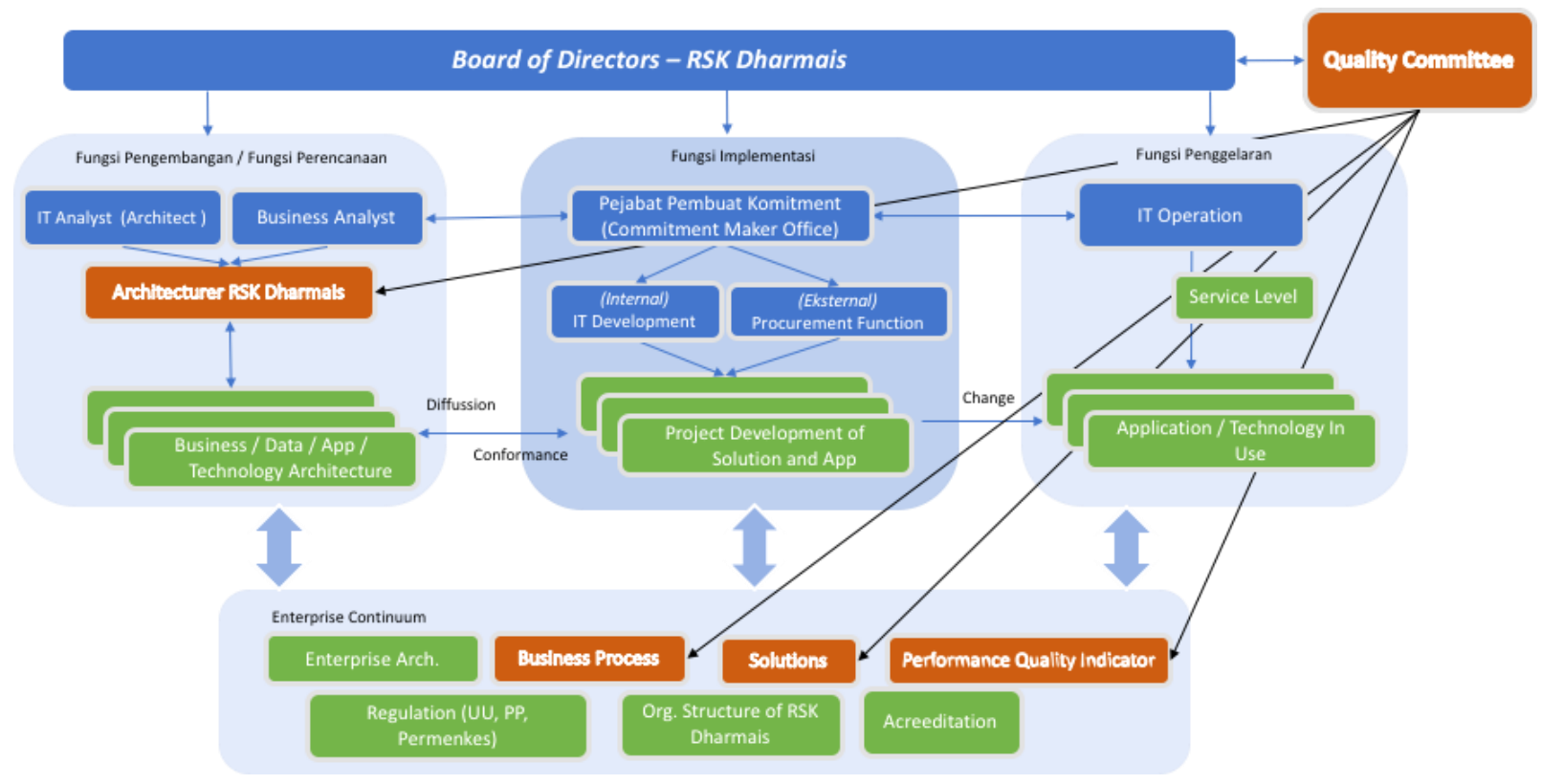

Figure 2. Proposed Architecture Governance Scheme.

With the purpose to reinforce the current role and responsibilities exist in the organization [24], then the proposed scheme for Architecture Governance Board in Dharmais is an improved scheme with 4 additional adjustments:

- Inclusion of Quality Committee to review, validate and provide recommendation to Management. This role includes deliverables of final Enterprise Architecture, and control of the implementation from Process Business improvement plan, Solution, and Indicators to measure the impact of implementation.

- Creation of IT Architect and Business Analyst function to execute the development of Enterprise Architecture, and process business improvement plan. Both roles will work together to map business processes and all the implications from business, legal and technical perspectives [25].

- Creation of IT Development team to provide the solutions required for the implementation of Architectures element.

- Creation of Dedicated IT Service Management team to handle Operation and Performance Management based on indicators.

\section{4-2-Architecture Vision Phase}

\section{4-2-1- Vision and Mission}

Dharmais have already developed its Business Strategy in 2020, which covers period of 2020-2024. It is called Rencana Strategi Bisnis 2020-2024 (RSB 2020-2024) and contain several Key information required to align the Architecture Development process to support the Business Objective. Vision and Mission of organization is included as shown below in Table 1 [12]. 
Table 1. Vision and Mission of RSK Dharmais.

\begin{tabular}{cc}
\hline Corporate Objects & \multicolumn{1}{c}{ Description } \\
\hline Vision & Becoming a "Caring and Smart" National Cancer Centre \\
\hline Mission & $\begin{array}{l}\text { 1. Providing Comprehensive and evidence-based Cancer treatment with Good Clinical Governance, } \\
\text { Patient-centered Care and Safety }\end{array}$ \\
& $\begin{array}{l}\text { 2. Conducting Cancer-related Education and Training } \\
\text { 3. Conducting Cancer-related Research to improve Cancer Patient-care } \\
\text { Managing National Cancer Load data }\end{array}$ \\
\hline
\end{tabular}

However, the vision and mission above is not capturing the essence of Dharmais as Cancer Hospital, as explained by stakeholders. This study improves the abstraction of vision and mission by re-draws it as Figure 3. From this redrawing, clearly shown that Dharmais as a Cancer Hospital, and a National Cancer means that Providing Medical Service (patient care), Providing Education and Training, Conducting Research, and Conducting Cancer Registration are the key activities of Dharmais. Research activities must play a key role in Dharmais, and the results are used to improve hospital capabilities to provide medical services to patient (outpatient and inpatient). This capability is also disseminated through Training and Education activities for other Hospital or external entity that requires it. Concurrently Dharmais is also appointed to collect and analyse national Cancer data (Hospital and Population based Cancer Registration) within its research capability, and share the information for the government or other relevant institution or communities.

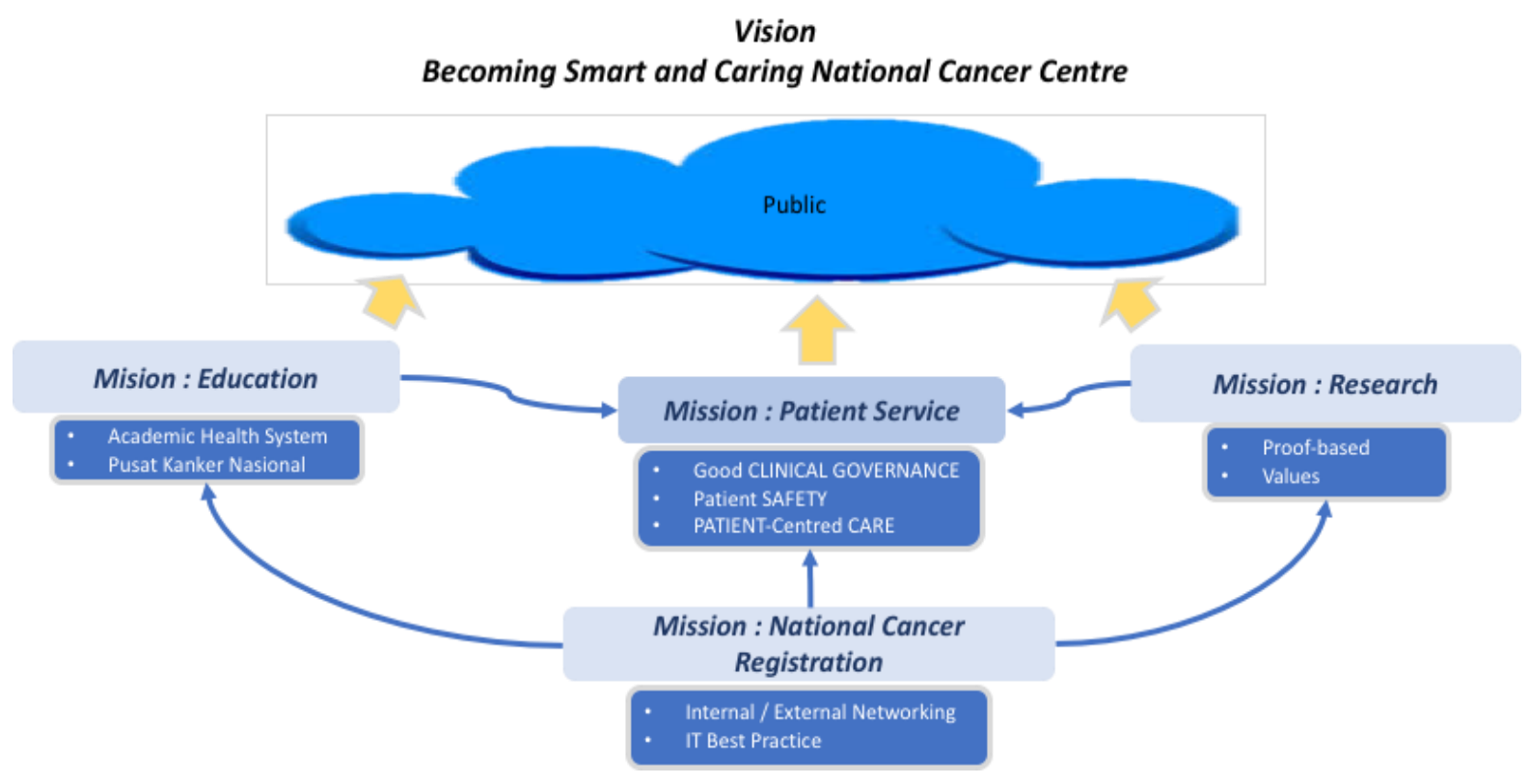

Figure 3. Vision and Mission RSK Dharmais.

\section{4-2-2- Value Chain Diagram}

As stipulated in the documents, the strategies to achieve vision are developed in Dharmais using SWOT and Balance Score Card (BSC), which resulted in a Strategy Map [12]. The strategy Map is consisted of 19 Strategies and distributed in 4 domains of: Financial Domain, Stakeholder's Perspective, Internal Process, and Learning / Growth. All this strategies are assigned to each related functions and units, and broken down into several Performance Indicators with assigned parameters. Unfortunately, this strategy map is not equipped with high level diagram of Value Chain that explain the processes in Dharmais.

To ensure the alignment is in place, this study develops a Value Chain for the hospital, using the previous information gathered. This Value Chain is capturing the primary activities within Dharmais that directly contributes to main value creation and the supporting activities that support the success of those primary activities. The mapping is using Porter's approach for Value Chain Diagram. Figure 4 is showing the result of the development of Value Chain. 


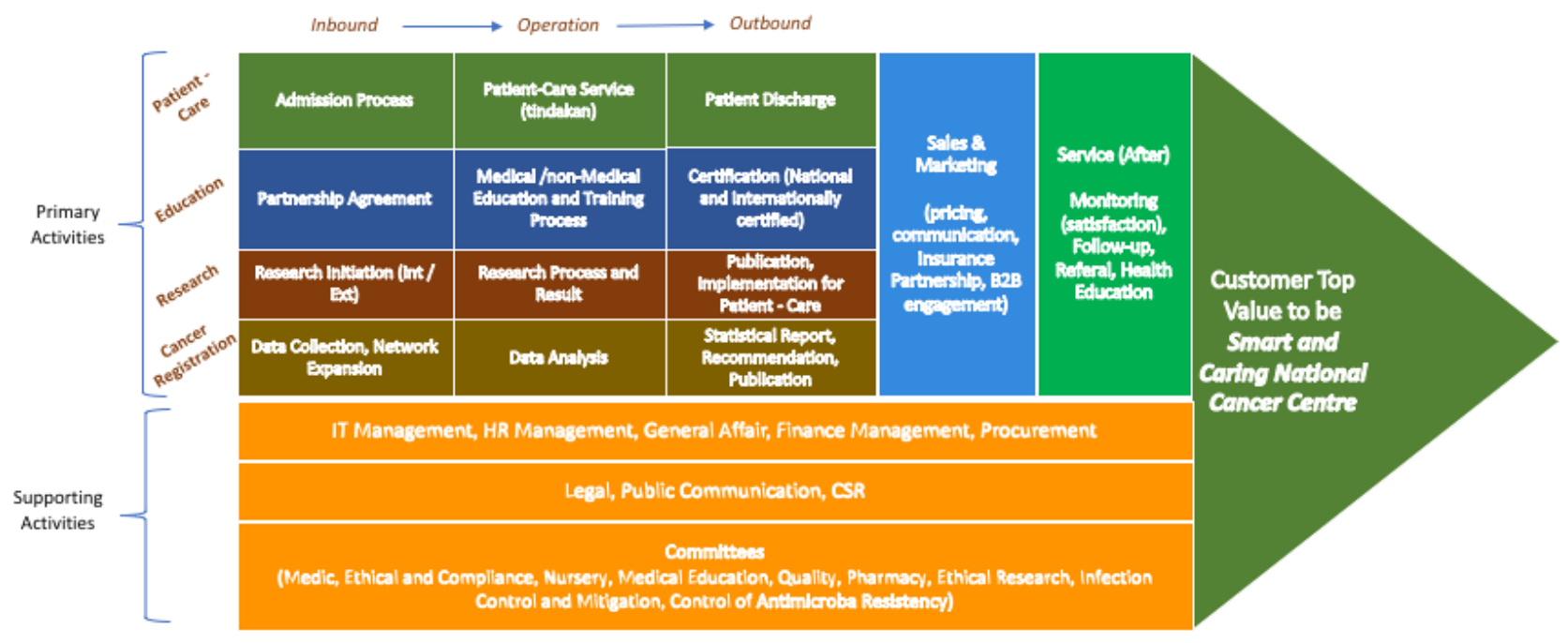

Figure 4. Value Chain Diagram of Dharmais.

Within this proposed Value Chain, this study categorize all the activities that interact directly with patients as primary, and the rest of activities without direct interaction with patients as supporting. The Value Chain is showing the Value Creation of 4 main missions in Dharmais (Services, Education, Research, and Cancer Registration), supported by other primary activities and also supporting activities. As already shown on the Strategy Map, those 4 main Value Creation Activities (Patient Care, Education, Research, and Cancer Registration) are main contributor to stakeholder's value, which then sequentially will be the keys in achieving the Vision. This is the basis for Business Process creation in Dharmais. This study is also proposing an elaboration of Sales \& Marketing Value activities which are directly related to the objective of being financially independent through increase of revenue, and Service activities which are directly influencing the achievement of positive engagement with customers / patients and also sustainability of revenue. Both are the keys to support Dharmais Strategy of increasing revenue and becoming less dependent to National Budget [12]

\section{4-2-3- Solution Concept Diagram}

This phase is also capturing the 'as-is' condition of the solution. This study divides current solution view into 4 layers which represent how the systems are interfacing with other layer to provide services. User Management Layer is the layer to put all the users as the stakeholders of Dharmais, Access Management Layer provides alternatives of access for each type of users, Application Management Layer shows several applications that Dharmais is using now, and Database Layer that shows several databases utilized within the system and its interconnectivity. The issues with current system is the absence of application support for primary activities of Education/Training and Research, lack of database integration, and also lack of integration on application (some application work in silo without interoperability).

This study develops target solution concept diagram with some improvements to address the deficiencies of current system. Those improvements are Integration of access management layer - by providing universal access to all 5 type of users using web-based, mobile-based, or desktop-client, Consolidation of application for each Value stream, Develop application to support Education and Research Value stream, Integrating database of Hospital to support Big Data, Develop API-based access to Database - to enable scalability and reusability of data access, and Develop Data analytics capability through Data Warehouse - providing new layer of Data Analytics and Business Intelligence to enhance the use of Data. Figure 5 is showing the target Solution Concept Diagram which already accommodates the abovementioned improvements.

\section{4-3-Business Architecture Phase}

\section{4-3-1-Organization Structure}

As public hospital directly under Ministry of Health, Dharmais is using standardized organization structure as shown in Figure 6 [26]. Management of the Hospital are led by President Director (Direktur Utama) which are supported by 4 others Director. They are monitored by Supervisory Board [27]. Below management layer, there are units to support each management role. There are also several non-structural committees to provide standardization, advices, or compliance review on Hospital activities and resources. Each of the committee reports to Management of Dharmais. 


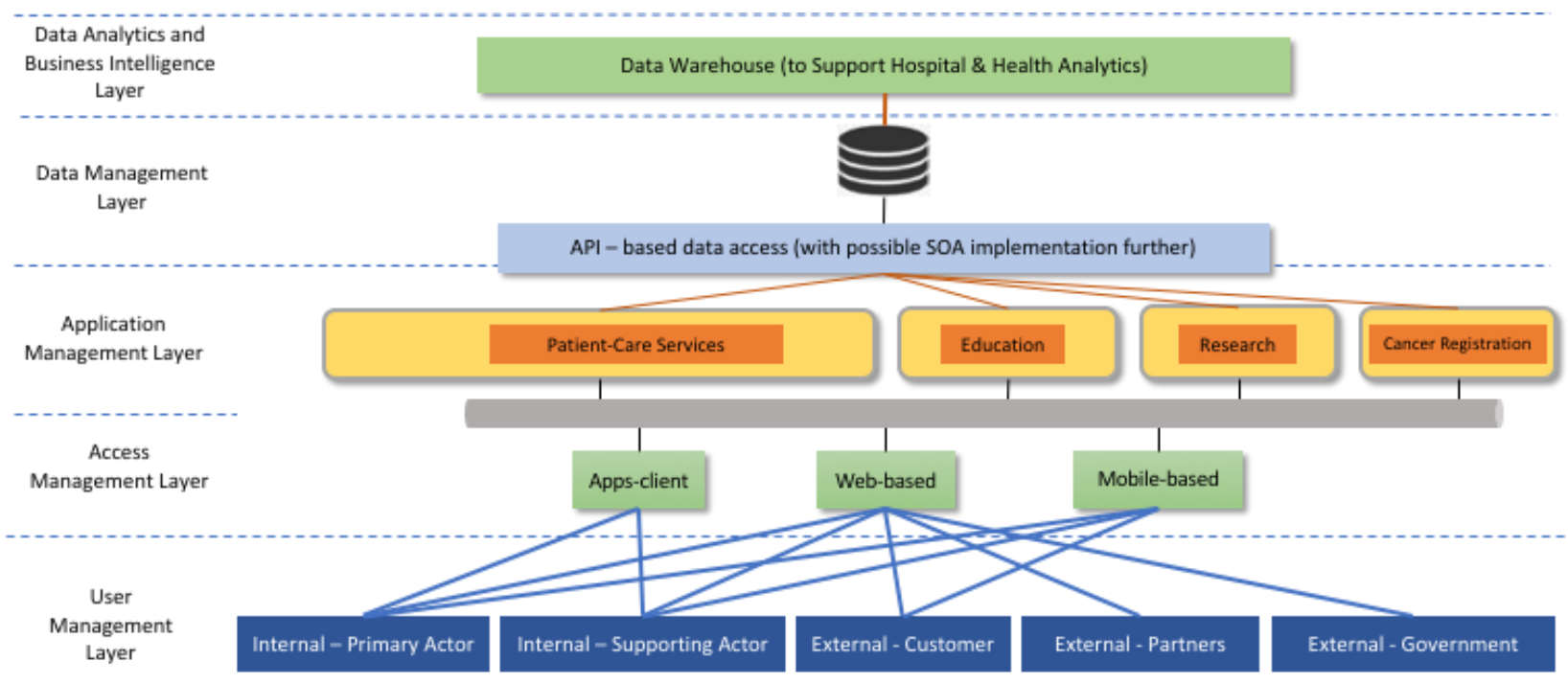

Figure 5. Target Solution Concept Diagram.

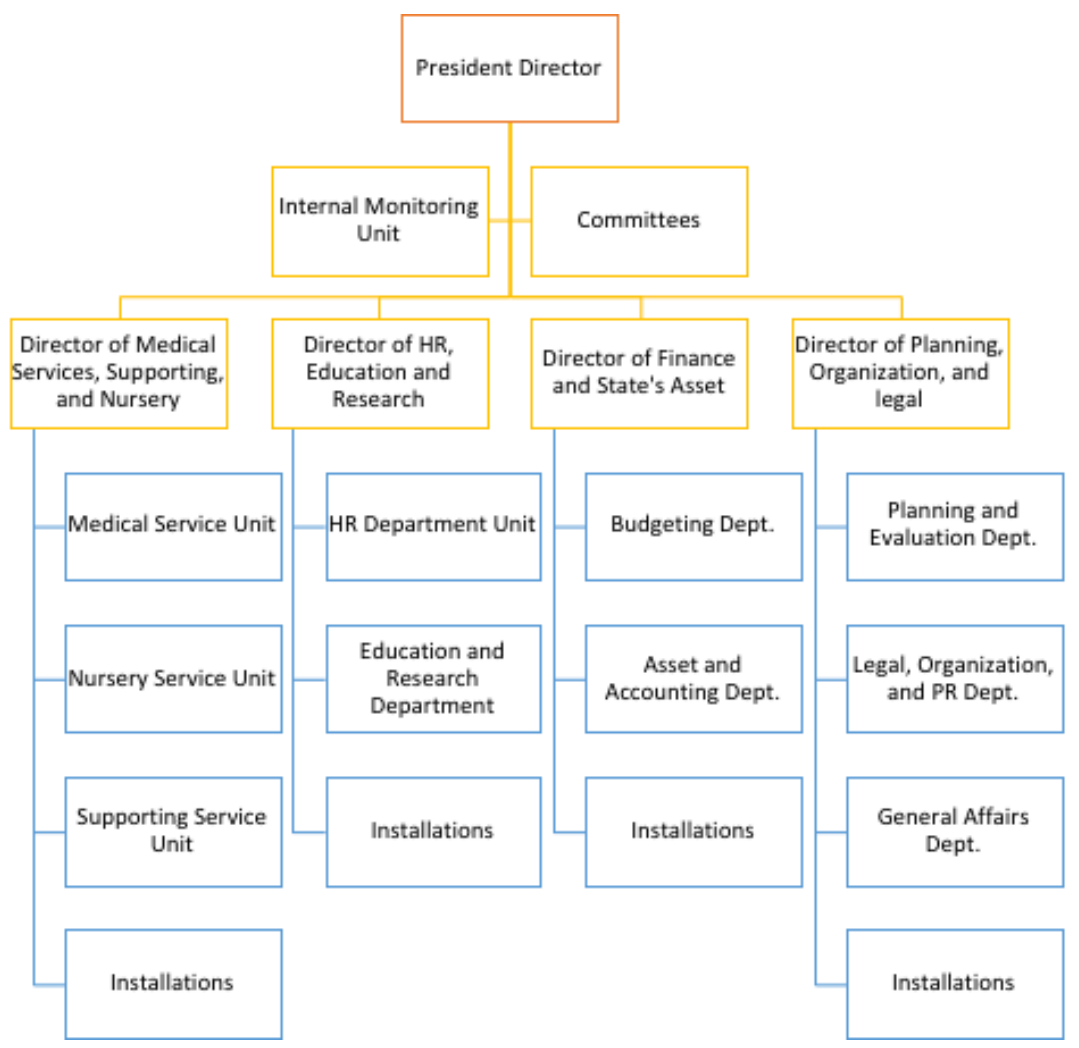

Figure 6. Organization Structure of RSK Dharmais (2020).

Continuing the discussion previously on Value Chain, it is interesting that this organization structure is missing several important elements. First, the primary activities of Education and Training, and Research, are put into 1 structure under Director of HR, Education and Research. Second, these 2 primary activities are merged. This indicates the less focus and narrow span of influence and control of it, which is contrary to proposed Value Chain. Regardless of the structure, it is imperative that those 2 primary activities need to be reinforced further.

\section{4-3-2- Business Process Diagram}

The current business processes is not available in Dharmais (latest version is year 2016), thus this study provides high level view of the business processes based on previous Value Chain, to be elaborated later by organization. As shown in Figure 7, the 4 primary activities is key to create values and they serve several market with different interest and values. Public is related to medical service, government is concerned with performance and public health information, B2B partners could serve as patients or partners in creating values, while healthcare providers are related to the sharing of competency of cancer treatment, etc. Further detail on the business processes within each primary activities this study is using BPMN tool [28] to provide samples of the processes. 


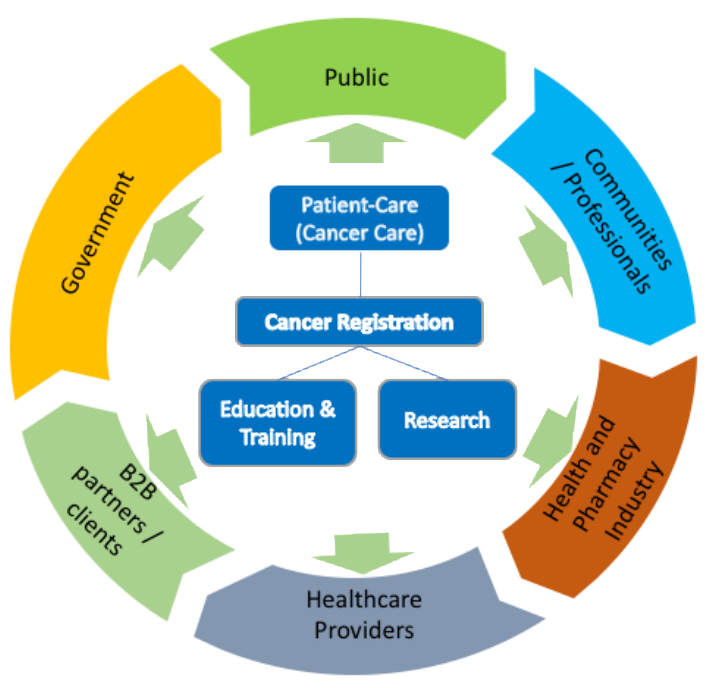

Figure 7. High-level Business Process Diagram.

For Sales \& Marketing value stream, this study deelops a proposed detailed tasks and positioning as part of Target Business Architecture. Further, this study breaks down the activities into 4 proposed main activities of Sales \& Marketing Value stream. Those activities are Developing Market Strategy - based on Segments, Developing Value Proposition - customized for each particular target market, Creating Pricing Strategy - which includes availability of internal resource allocation in Dharmais, and Developing Communication Plan - through opening channels and partners to leverage Dharmais strengths. Figure 8 is showing how those 4 activities relate within Sales and Marketing stream.

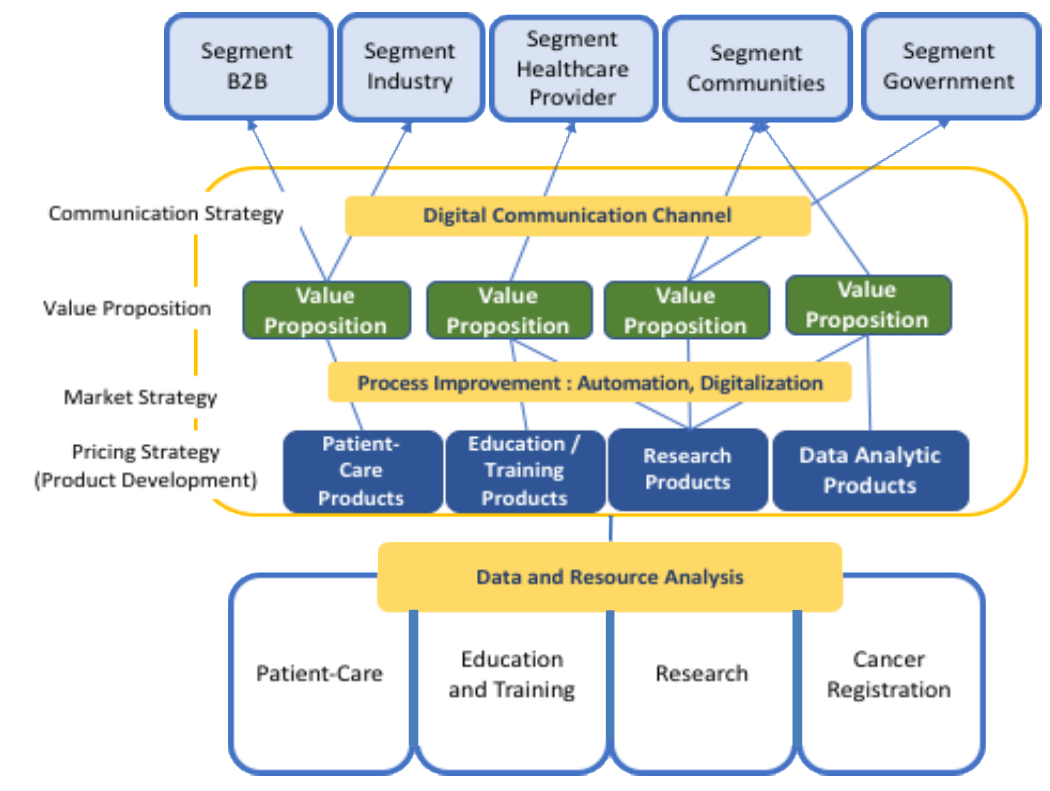

Figure 8. Sales and Marketing Activities Layer Diagram.

Sales \& Marketing value stream needs to have access to all data of resource usage to define the cost and pricing strategy. This data is used to develop market strategy using elements of architecture, which then enable the team to finalize the value proposition to each market segments Dharmais plan to serve. The final part of this value stream is the Communication plan through traditional and mainly Digital Channels.

\section{4-3-3- Data Management Process Diagram}

Hospital is an entity with abundant of data of highly valuable resources which are beneficial to improve health management in general [29]. Dharmais is not only appointed as National Cancer Hospital but also as National Registration Centre for Cancer [30]. Thus, it is only logical that one of primary activities in Dharmais is to provide high quality data management for Cancer, from detection, treatment, and mortality. For that reason, for Dharmais to have the competitive advantage as defined in the strategy map, top management must have a clear understanding of the data flows in the organization, application, and infrastructures across business units [31, 32]. This study finds a written guidance for business processes for data management in Dharmais [33], which covers not only cancer-related data but also all data generated from Dharmais operation as hospital (finance, performance, employee, etc.). 
To ensure the alignment of this policy with proposed value chain, this study proposes separation of Data Creation processes and Data Operationalization processes in Dharmais. Data creation process relies on the capability of business to collect all relevant data using multiple technique and media (automatic entry by system, manual entry, event-based / trigger-based / hybrid), while Data Operationalization relies on capability to disseminate data on the right time, right user with high level of accuracy. Figure 9 shows target processes of data creation as improved from current processes and Figure 10 shows how the process of Disseminating Data from database to users through conceptual solution design by following the CRUD matrix that is explained later in Data Architecture discussion.

On data collection phase, the development of EA should ensure that all data request has gone through thorough analysis from EA standpoint to capture the value creation and alignment with strategic objectives. This additional criteria is significant to optimize the use of resource in preparing, developing and managing the data creation, storage and distribution later on. For data operationalization phase, the authority of each function to access data should also be defined to ensure compliance with security principles. This is why the CRUD matrix should come in higher priority.

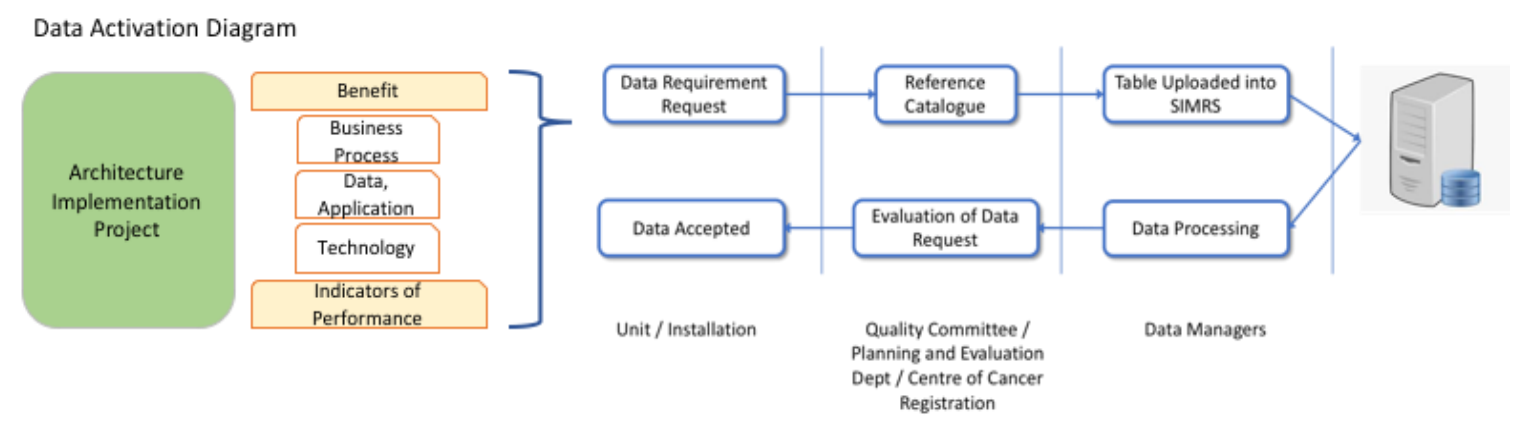

Figure 9. Target Data Creation Processes.

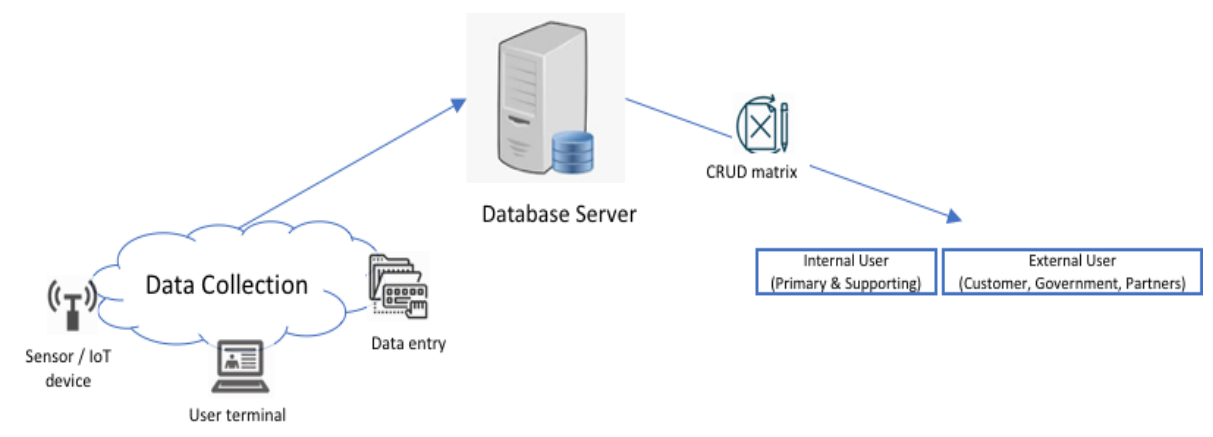

Figure 10. Target Data Operationalization Processes.

\section{4-3-4- IT Installation Unit}

As captured in Strategy Map, IT function has its own objectives of developing application (= 3 application), which may in conflict with the numbers of solution requested by each business user (Quality Committee alone was requesting 3 application to be ready in 2021). Secondly, from Architecture Governance adjusted scheme stated the existence of IT architect function, IT development team, and IT Operation team that will be having different objectives and roles. Thus, this study proposes a Service Management approach to manage the Target business architecture of IT function in Dharmais.

Figure 11 is developed to map the elements of Vision (integrated and self-dependable / in-house) and Mission (data accuracy, solution fulfillment, high quality Operation - SLAs, high competency) of IT Installation Unit, into Service Management approach using ITIL v3. [34].

As shown above, it is possible to map all elements of IT vision and mission (considered to be IT's roles and objectives) into 5 different functions in Service Management approaches. However, for the sake of resource optimization, it is possible to squeeze 5 functions into ( $\mathrm{min}$ ) 2 units (Planning unit and IT Unit) or more (Planning Unit, several Business user Units, dan IT Unit). This mapping should follow management decision and guidance for Target Business Architecture of Dharmais. 


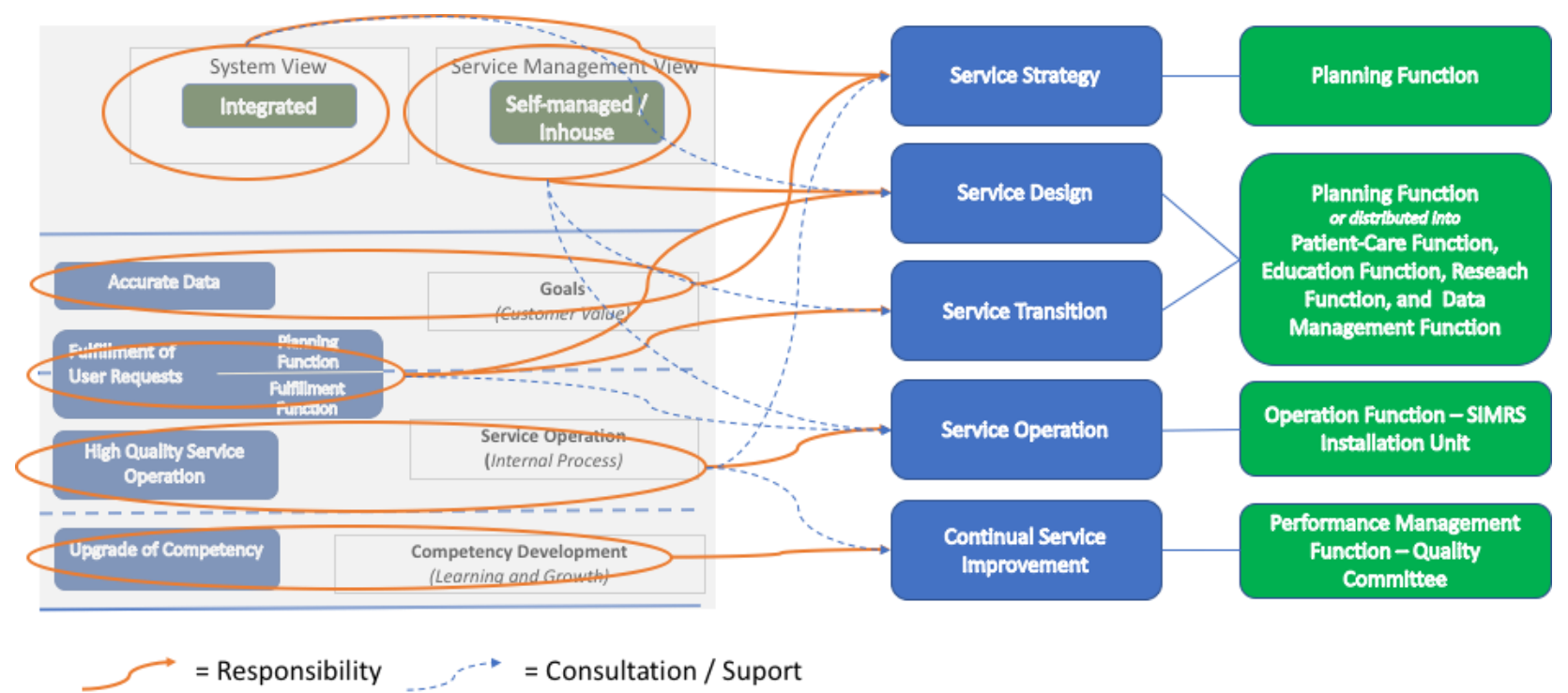

Figure 11. Mapping of baseline IT function into Service Management ITIL v3.

\section{4-4-Information Architecture Phase (Data Architecture)}

From Data architecture point of view, this study finds out 4 methods of Database interaction in Dharmais:

a) Direct Database access: This approach is used in majority of application. It allows integration of all database for each application / modules. It is implemented by putting database access (username and password) on the source code of each application to access required database, and compiled.

b) API connection: This approach is used for DBEX application only. The API is used reciprocally between DBEX and other applications or modules which needs access to it.

c) Dump Data usage (1-way database usage): This approach is used for LIS (laboratory Information System) only. This way, LIS will dump all the data in a file, and other application will retrieve the data and insert into the database with pre-arranged format and separator.

d) Separate (island) Database: This approach is basically leaving the database alone and not-connecting it to any application or modules. This is done only for Application CanReg (Cancer Registration).

Those approaches to manage Data is not future proof, and hindering the achievement of vision "Smart". The target architecture needs to integrate this scattered Data access with more scalable yet flexible approach. One alternative is by using combined TOGAF and SOA approach to develop interoperability and integration [35]. However, this study also proposes to complete the allocation of CRUD matrix based on earlier Value chain and business processes as precondition for this database integration.

\section{4-5-Information Architecture Phase (Application Architecture)}

During this phase, this study finds out that Dharmais is using 28 Applications, by which 25 applications are developed in-house, and 3 applications were developed by external developers. There are total almost 600 modules and 25 databases to support those 28 Applications. This information are put into an Application Portfolio Catalogue as baseline. Majority of the applications are still provided based on ad-hoc requirement and highly impacted by policy and guidance taken directly from Management of organization. In general, it has low level of scalability, while Business requires a more agile and flexible solution in near future. From Interoperability point of view, there are applications used in silo, without capability to share the access and data to others. In order to increase the impact of this portfolio, interoperability of the applications running needs to exist in Dharmais [32]. For target Architecture, it is proposed to map each application based on the main activities (as detailed in Value Chain Diagram) it served. Further, each process that creates value should be optimized to provide efficiency and effectiveness through IT support. For each application, this study also develops Application Actor Catalogues and Application Use-Case Diagram.

Another potential for development of target architecture, is the Implementation of API in Dharmais. This API concept is aligned with the mandate of Dharmais as National Cancer Registration to share the data to users or groups with interest in Cancer [30]. This API will provide access to its Database and Function, for Internal and External user. The proposed setup is by implementing an API server to manage access to Database or Application server, and allowing certain access from internal apps or even external apps. The diagram is shown in Figure 12. 


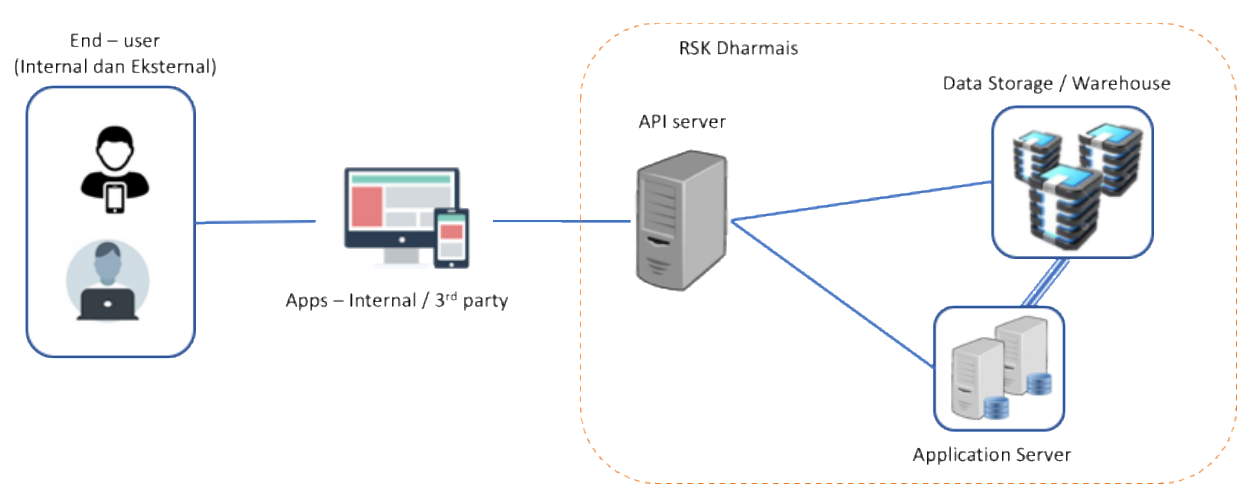

Figure 12. API diagram for Dharmais.

\section{4-6- Technology Architecture Phase}

Dharmais is using several types of Server technology to support the backend Processing capacity. Mainly the components are divided into Application Servers, Database Servers, and Storage Servers. As for the Network elements, Dharmais is using Router, Core Switches, Distribution Switches, Firewall, and Wi-Fi Access Point. All those data are put into Technology Portfolio Catalogue as baseline information.

\section{4-6-1- Cloud Storage}

Currently, Dharmais is using internal Storage using special Storage Servers with capacity up to 47 TB, and located in the same room with all the application servers as Dharmais Data Centre. Unfortunately this data centre is reliant to UPS with shared capacity (in average 15 minutes backup time) and genset from Building. There has been case where power is lost in the datacentre locally and storage servers shutdown, which is impacting major data loss for Dharmais.

With higher availability and focus on Big data for future, Target architecture for Dharmais includes alternative of using Cloud storage for backup. Nevertheless, this target objective shall thoroughly analyse the elements of cloud adoption steps such as governance affecting the plan, law and regulation compliance, inclusion in the final architecture, and technical aspects (and security) [25]. Specifically for this case, this study develops analysis for cloud adoption using 3 areas which are Compliance Criteria - referring to Ministry Decrees and Accreditation compliance, Business Environment - alignment with Business Objective and Cost Effectiveness, and Risk Mitigation - related to Continuity, Security, and Quality Assurance.

In order to provide higher efficiency in data access and storage cost, this study proposed differentiation of 3 types data - hot data, cold data, and static data, to be stored in both in-house datacentre and cloud storage [5]. Hot data is meant for data with less than 3 months old for last access, cold data is data with last access less than 6 months old, and static data is data with more than 6 months last access. It is summarized in Table 2.

Table 2. Target Data Policy for Cloud Storage.

\begin{tabular}{|c|c|c|c|}
\hline \multicolumn{4}{|c|}{ Data Storage Policy } \\
\hline Data Type & Description & Validity & Location \\
\hline Hot Data & Data that need to be accessed to support Operational activities of the Hospital & Last accessed $<3$ months & Local Storage \\
\hline Cold Data & $\begin{array}{l}\text { Data that need to be accessed regularly within certain interval time (medium } \\
\text { term) }\end{array}$ & Last accessed $<6$ months & Cloud Storage \\
\hline Static Data (Archive) & $\begin{array}{l}\text { Data that are archived, and need to be accessed in long term period. Usually } \\
\text { required for Compliance / Audit. }\end{array}$ & Last accessed $>6$ months & Cloud Storage \\
\hline
\end{tabular}

\section{4-6-2- Internet Access Diagram}

This study finds the configuration for Internet Access is having 1 level redundancy, which is fibre-core redundancy (by provider). However, the access route entering Dharmais compound is still using 1 single duct, which means no geographical redundancy. To improve on redundancy, it is proposed to upgrade the target Architecture for Network Access by using 4-tier redundancy using CPE redundancy, Access Router redundancy, Transmission media redundancy, Point-of-Presence (PoP) redundancy, and Provider redundancy. This concept is shown in Figure 13. 


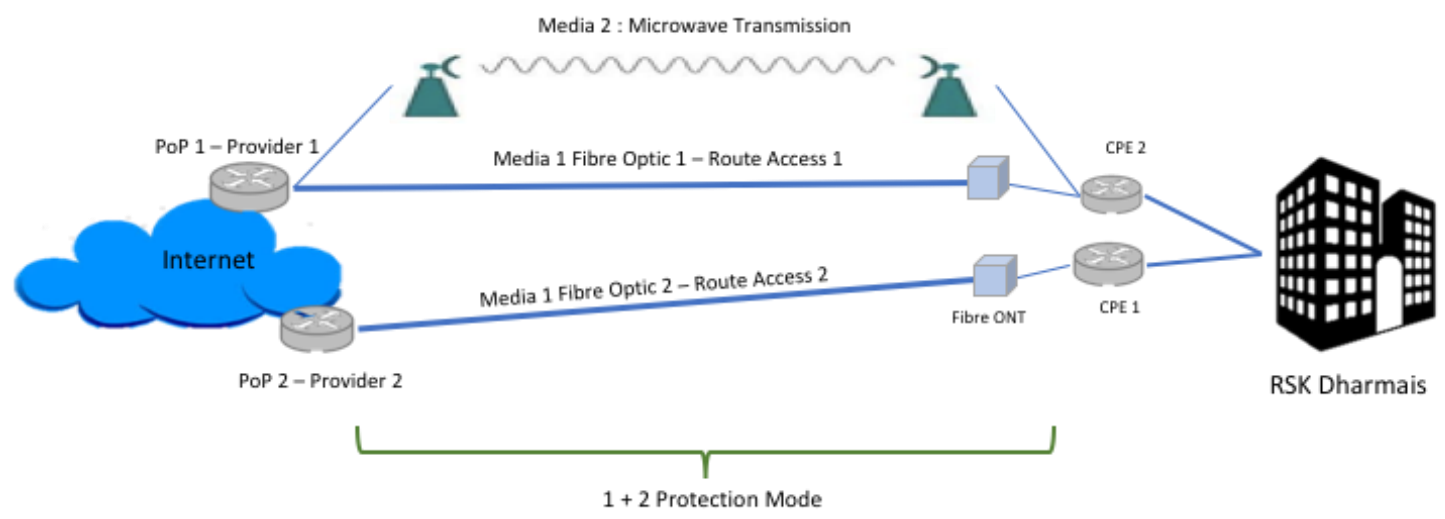

Figure 13. Target Network Access Redundancy Diagram.

With this configuration, while the main physical connection is Fibre Optic 1, Dharmais will have additional 2 physical layer protection using Fibre Optic 2 and Microwave Transmission. And further strengthened with different Route Access (Route Access 1 and Route Access 2) into Dharmais, which comes from different network PoP (PoP 1 and PoP 2) from different Internet Provider (Provider 1 and Provider 2). This study also responds to a challenge regarding compliance with government regulation on feasibility of using 2 providers. This study finds the solution by providing benchmark case in other government entity. The key is on the definition of scope of work for providers which needs to be clearly defined as "main Internet Provider" or "backup Internet provider".

\section{4-6-3- Network Topology Diagram}

Dharmais Internal Network are connected using 3 medias: Fibre Optic cables, UTP Cat 6 cables, and Wireless access. This medias connect all Network Devices of Router, Switches, and Wi-Fi devices. For the target architecture, this study proposes the addition of redundancy for network connectivity, implementation of Cloud Storage, and use of RFID to enable data gathering (collection) for hospital devices, equipments, and facilities. The diagram are shown in Figure 14.

Internet

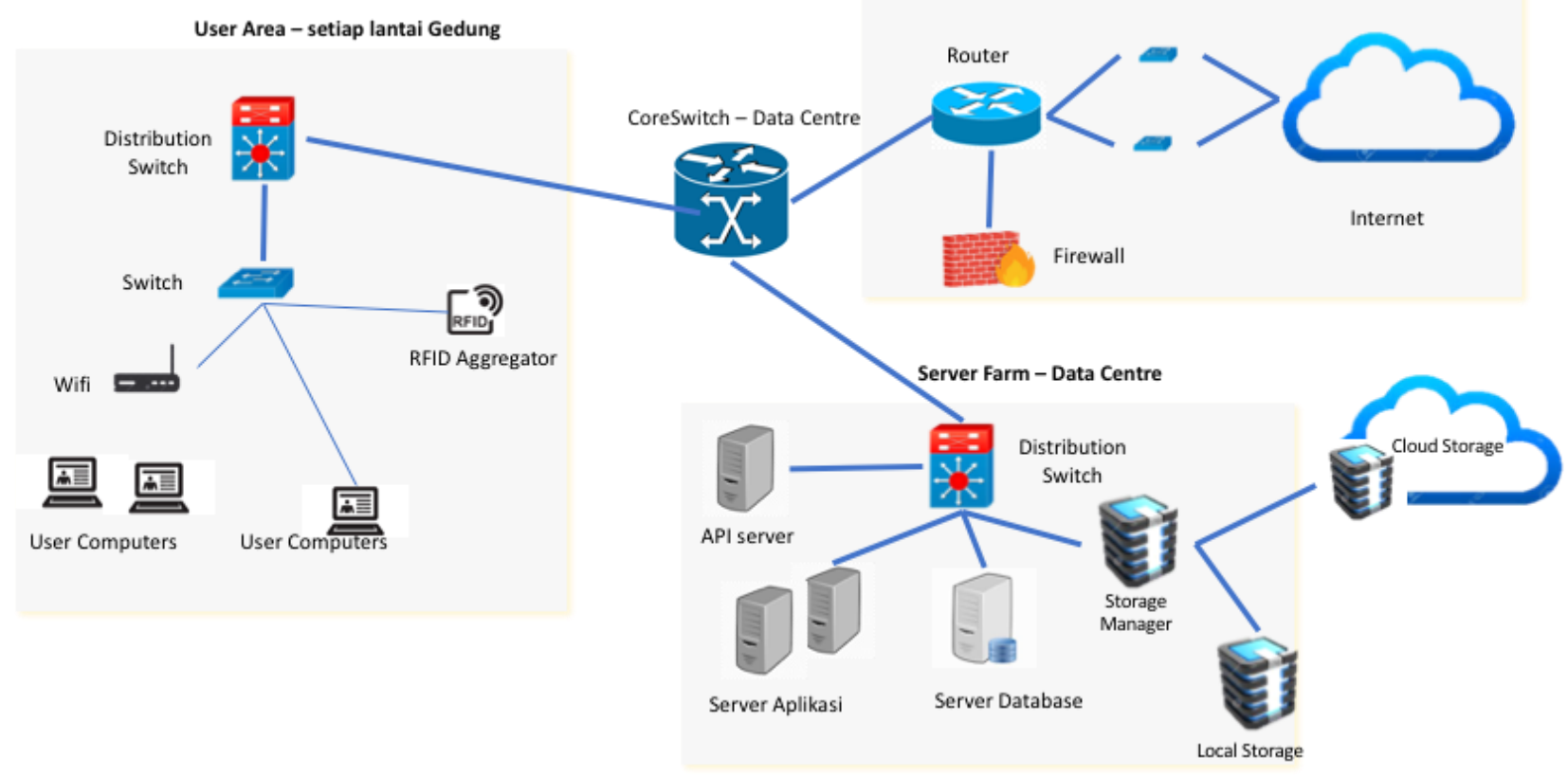

Figure 14. Network Topology Target Diagram.

\section{4-7-Opportunity and Solution Phase}

From all previous phase, there are identified gap and improvement analysis distributed in Business domain (10 gaps), Data domain (7 gaps), Application domain (10 gaps) and Technology domain ( 7 gaps). Also additional 2 gaps are added from Preliminary and Architecture Vision, which total is 36 gaps identified. The gaps can be a totally new recommendation, or upgrade from current condition.

All these gaps are arranged as recommendation to respond to each corresponding 4 issues identified prior to this study, and the result is shown below in Table 3. 
Table 3. Consolidation and Mapping of Gap Analysis.

\begin{tabular}{|c|c|c|c|c|}
\hline Objectives & No. & Recommendation & Source of Gap & Type \\
\hline \multirow{4}{*}{$\begin{array}{l}\text { Increasing ownership and } \\
\text { responsibility of business } \\
\text { users }\end{array}$} & 1 & Development of Value Chain / Formalize & Architecture Vision & New \\
\hline & 2 & Development of Service primary activities & Architecture Business & New \\
\hline & 3 & Implementation of Data Management Process & Architecture Business & New \\
\hline & 4 & Strengthening of Training and Education processes & Architecture Business & Upgrade \\
\hline \multirow[t]{3}{*}{ Business Strengthening } & 5 & Strengthening of Research processes & Architecture Business & Upgrade \\
\hline & 6 & Upgrading / Strengthening of Sales and Marketing processes & Architecture Business & Upgrade \\
\hline & 7 & Decision on Data trustee for Hospital & Architecture Data & Upgrade \\
\hline \multirow{3}{*}{$\begin{array}{l}\text { Aligning IT Roadmap and } \\
\text { Strategy with Business } \\
\text { Strategy of the Hospital }\end{array}$} & 8 & Development of new Architecture Governance scheme & Architecture Vision & New \\
\hline & 9 & Creation of new role : Business Analyst & Architecture Business & New \\
\hline & 10 & Creation of new role : IT Architect & Architecture Business & New \\
\hline \multirow{2}{*}{ Strategy Alignment } & 11 & Creation of new role: Service Implementation & Architecture Business & New \\
\hline & 12 & Enabling access of Planning team to Finance and Performance & Architecture Data & Upgrade \\
\hline \multirow{16}{*}{$\begin{array}{l}\text { Maximize the use of IT as } \\
\text { Competitive Advantage } \\
\text { for Hospital }\end{array}$} & 13 & Strengthening Development process using ITIL v3 & Architecture Business & Upgrade \\
\hline & 14 & Implementation of Data Warehouse & Architecture Data & New \\
\hline & 15 & Database Consolidation for all primary and supporting streams & Architecture Data & New \\
\hline & 16 & Development of Cloud Strategy & Architecture Data & New \\
\hline & 17 & Creation of CRUD Matrix for Data component & Architecture Data & New \\
\hline & 18 & Development of Data Collection process & Architecture Data & Upgrade \\
\hline & 19 & Implementation of API for Database access & Architecture Data & Upgrade \\
\hline & 20 & Development of Training and Education application suite & Architecture Application & New \\
\hline & 21 & Development of Research application suite & Architecture Application & New \\
\hline & 22 & Development of Sales and Marketing application suite & Architecture Application & New \\
\hline & 23 & Development of Service application suite & Architecture Application & New \\
\hline & 24 & Integration of Facility Mgt to HIS & Architecture Application & New \\
\hline & 25 & Integration of CanReg apps to HIS & Architecture Application & Upgrade \\
\hline & 26 & Upgrade of HR application for Competency Development & Architecture Application & Upgrade \\
\hline & 27 & Integration of Finance apps - ERP system & Architecture Application & Upgrade \\
\hline & 28 & Implementation of Cloud Redundancy for Storage & Architecture Technology & New \\
\hline \multirow{8}{*}{$\begin{array}{l}\text { Improving Service Quality } \\
\text { and Reliability of IT } \\
\text { Operation }\end{array}$} & 29 & Strengthening of IT Operation and Support using ITIL v3 & Architecture Business & Upgrade \\
\hline & 30 & Development of application for IT Operation & Architecture Application & Upgrade \\
\hline & 31 & Provision of 2 fibre access route & Architecture Technology & New \\
\hline & 32 & Provision of $2^{\text {nd }} \mathrm{CPE}$ for Network Connectivity & Architecture Technology & New \\
\hline & 33 & Upgrade Data Centre in new Building & Architecture Technology & Upgrade \\
\hline & 34 & Review feasibility of using 2 redundant sub-stasion for Power & Architecture Technology & Upgrade \\
\hline & 35 & Upgrade Internet access by using 2 providers & Architecture Technology & Upgrade \\
\hline & 36 & Upgrade Internet access by microwave backup transmission & Architecture Technology & Upgrade \\
\hline
\end{tabular}

In formulating the plans for each item above, there has been several factors that need to be considered based on the nature of Dharmais organization, culture and environment. This study is using 5 factors to be considered, namely, Compliance to Regulation, Technical, Economic and Financial, Environment and Social, and Risk Analysis.

\section{4-8- Implementation and Change Management}

The output of previous phase are accommodated into Target Architecture of Dharmais, and the gaps with baseline Architecture are identified to formulate "improvement actions" or "projects' that need to be implemented. However, to implement this on operational level, Dharmais does not have any specific function or role that is equipped with relevant Task and Authority to be consistently managing the implementation of this improvement. Also, from Governance point of view, there has no function and structure within organization that was given roles to govern any future implementation of IT roadmap other than the IT unit, while the roadmap is clearly key aspect to achieve high quality investment impact on IT [36]. 
Further review of current business processes and job description have shown that the level of authority and coverage of the implementation was not properly aligned. For this reason, thus it is proposed to use the same governance framework earlier (Figure 2) as the scheme to create an ownership during implementation of Target Architecture. This phase of operationalization of EA into projects operationalization needs to consider the key aspects of the sociocultural climate in Dharmais which include autonomy (in several units / departments), flexibility, and specific demand for locally adapted system [37].

On this proposal, each implementation will involve CEO as accountable actor, which also serve as the Project Sponsor. The remaining directors will be accountable for the development of Programs / Projects, with success criteria (indicators) to be validated and recommended by Quality Committee. The next actions of Activating the resource, Guiding the execution, Managing change management (locally - as impact of implementation), and Managing stability will be the accountability of each Head of Department or each Head of relevant Installation unit. Then, on final closure of implementation (of each project), the handover of the project to Operational entity will be done by Head of Department / Installation to the IT Operation team.

\section{5- Conclusion}

This study has provided the full architecture work for Dharmais from baseline condition (Current) to the Target Architecture. At the end of the processes, this study has identified 36 gaps from all the sequential phases of TOGAF ADM. Most notably, the gaps stem from some primary activities that exist in the proposed Value Chain diagram but not yet supported (minimum support) with proper business processes within the organization, such as Education and Training activities, Research activities, Cancer Registration activities, Sales and Marketing activities, and Service activities. Further, all those gaps are converted as recommendation of improvement, and mapped into 4 objectives of this study, which generate 7 recommendations to improve Ownership of Business users, 5 recommendations to align Business vs. IT strategy, 16 recommendations to maximize IT use to create Competitive Advantage, and 8 recommendations to Improve IT Operation Performance. The work of the study also shows how Enterprise Architecture (TOGAF ADM) can pinpoint the specific gaps (and improvement) within Business domain to increase awareness and ownership of the business users (i.e. with the need of having clear Value Chain). Furthermore, this Enterprise Architecture framework still also maintain the capabilities to pinpoint specific improvement for IT-related issues, such as the need to have stronger service operation team with high standard of quality (i.e. with the need of having redundancy to avoid major outage and data lost). TOGAF has also provided valuable guidance to identify the lack of governance process in Dharmais. And combined with internal research within Dharmais, this study have successfully developed Architecture Governance scheme by optimizing existing units to expand the roles (Quality Committee), splitting the roles (IT Installation Unit), and re-arranging interaction between current units to improve the governance process in Dharmais.

\section{6- Declarations}

\section{6-1-Author Contributions}

Conceptualization, analysis, writing and editing, A.S.G and A.A; reviewing, editing, supervising, A.S.G. All authors have read and agreed to the published version of the manuscripts.

\section{6-2-Data Availability Statement}

Data for this study is provided by Dharmais Cancer Hospital. No sharing of duplication of the data permitted without prior approval from Dharmais. Data and Information generated by this study is available from the author, thus sharing and reuse is permitted.

\section{6-3- Funding}

The authors received no financial support for the research, authorship, and/or publication of this article.

\section{6-4- Conflicts of Interest}

The authors declare that there is no conflict of interests regarding the publication of this manuscript. In addition, the ethical issues, including plagiarism, informed consent, misconduct, data fabrication and/or falsification, double publication and/or submission, and redundancies have been completely observed by the authors.

\section{7- References}

[1] Xudong Lu, Huilong Duan, Haomin Li, Chenhui Zhao, and Jiye An. "The Architecture of Enterprise Hospital Information System.” 2005 IEEE Engineering in Medicine and Biology 27th Annual Conference (2005). doi:10.1109/iembs.2005.1616106.

[2] Bonnet, M. J. a. "Measuring the Effectiveness of Enterprise Architecture Implementation." Master's thesis, Delft University of Technology, Delft, Netherlands, (2009). 
[3] Sabooniha, Nazanin, Danny Toohey, and Kevin Lee. "An Evaluation of Hospital Information Systems Integration Approaches." Proceedings of the International Conference on Advances in Computing, Communications and Informatics - ICACCI'12 (2012). doi:10.1145/2345396.2345479.

[4] J. Burke, "Where is Enterprise Architecture in HealthCare?" Information Wee - Healthcare Digital Issue, 2013. Available online: https://www.informationweek.com/healthcare/leadership/where-is-enterprise-architecture-in-healthcare/d/d-id/898882? (accessed on February 2021).

[5] Herman, Sukrina, Asti Amalia Nur Fajrillah, and Rachmadita Andreswari. "Perancangan Enterprise Architecture Pada Fungsi Rekam Medis Rumah Sakit Dengan Pendekatan Togaf ADM.” Jurnal Rekayasa Sistem \& Industri (JRSI) 4, no. 01 (July 19, 2017): 37-46. doi:10.25124/jrsi.v4i01.199.

[6] N. A. N. Dewi and I. N. Y. A. Wijaya, "Analisis Architecture Teknologi untuk Meningkatkan Layanan RS dengan Menggunakan TOGAF ADM," Journal Teknologi Informasi dan Komputer, (2018).

[7] A. F. Kanz, Perencanaan Strategis IS/IT di PUSDATIN KEMENDAGRI Menggunakan Framework Enterprise Architecture TOGAF, Jakarta: Program Studi Magister Manajemen Sistem Informasi - Universitas Bina Nusantara, (2019).

[8] A. M. Abdul Hakim, Perancangan Arsitektur Teknologi Informasi untuk Mengotomatisasi Proses Bisnis Enterprise dengan Menggunakan TOGAF ADM - Studi Kasus PT Aero Systems Indonesia, Jakarta: Program Magister Manajemen Sistem Informasi - Universitas Bina Nusantara, (2019).

[9] A. A. Abdurachman, Penerapan Framework TOGAF dalam Perencanaan Strategis Sistem Informasi Studi Kasus pada Kementerian Pertanian, Jakarta: Binus University Graduate Program, (2018).

[10] K. Ahsan, H. Shah and P. Kingston, "HealthCare Modelling through Enterprise Architecture: A Hospital Case," Seventh International Conference on Information Technology, (2010).

[11] Hermawan, R A, and I D Sumitra. "Designing Enterprise Architecture Using TOGAF Architecture Development Method.” IOP Conference Series: Materials Science and Engineering 662 (November 20, 2019): 042021. doi:10.1088/1757$899 \mathrm{x} / 662 / 4 / 042021$.

[12] R. K. Dharmais, "Rencana Strategi Bisnis 2020 - 2025," RS Kanker Dharmais, Jakarta, (2020).

[13] Sessions, R., and John deVadoss. "A Comparison of the Top Four Enterprise Architecture Approaches in 2014." Microsoft Corporation (2014): 1-55.

[14] Bui, Quang Neo. "Evaluate Enterprise Architecture Frameworks Using Essential Elements." Communications of the Association for Information Systems 41, no. 8 (2017): 121-149. doi:10.17705/1cais.04106.

[15] Purnawan, Dilla Anindita, and Kridanto Surendro. "Building Enterprise Architecture for Hospital Information System." 4th International Conference on Information and Communication Technology (ICoICT) (May 2016). doi:10.1109/icoict.2016.7571907.

[16] Pasaribu, Faizal Asrul, Jordan Hakiki Sipahutar, Bastian Paskal Situmorang, Sfenrianto Sfenrianto, and Emil R. Kaburuan. "Designing Enterprise Architecture in Hospitals Group." 2019 International Conference on Information and Communications Technology (ICOIACT) (July 2019). doi:10.1109/icoiact46704.2019.8938526.

[17] M. Zahrudin, "Perencanaan Strategis Sistem Informasi pada Penyelenggaraan SIKN dan JIKN dengan Menggunakan Framework TOGAF”, Jakarta: Binus University Graduate Program, (2018).

[18] A. Amyus, "Perancangan Enterprise Achitecture Digital Payment pada PT XYZ Menggunakan Framework TOGAF”, Jakarta: Graduate Program - Universitas Bina Nusantara, (2019).

[19] M. Ibrohim, "Perancangan IT BluePrint dengan TOGAF untuk Pengembangan Teknologi Informasi”, Jakarta: Binus University Graduate Program, (2019).

[20] S. Kotusev, "Enterprise Architecture is not TOGAF," (2016). Available online: http://www.bcs.org/contenconWebDoc/55547 (accessed on March 2021).

[21] The Standish Group, "CHAOS Report," The Standish Group International, Inc., (2015).

[22] J. Bloomberg, "Is Enterprise Architecture Completely broken?" July 2014. Available online: https://www.forbes.com/sites/jasonbloomberg/2014/07/11/is-enterprise-architecture-completely-broken/?sh=55e0d7fc3710 (accessed on March 2021).

[23] Erasmus, Wikus, and Carl Marnewick. "An IT Governance Framework for IS Portfolio Management." International Journal of Managing Projects in Business 14, no. 3 (August 23, 2020): 721-742. doi:10.1108/ijmpb-04-2020-0110.

[24] Hussein, Surya Sumarni, Mohd Naz'ri Mahrin, Nurazean Maarop, and Nur Azaliah Abu Bakar. "Development and Validation of Enterprise Architecture (EA) Readiness Assessment Model.” International Journal on Advanced Science, Engineering and Information Technology 10, no. 1 (February 21, 2020): 157. doi:10.18517/ijaseit.10.1.9007. 
[25] Singh, Mayank, Kuldeep S. Tanwar, and Viranjay M. Srivastava. "Cloud Computing Adoption Challenges in the Banking Industry." 2018 International Conference on Advances in Big Data, Computing and Data Communication Systems (icABCD) (August 2018). doi:10.1109/icabcd.2018.8465412.

[26] Ministry of Health Republic of Indonesia, Permenkes 46th 2017 tentang Strategy e-Health Nasional, Government of Indonesia, (2017).

[27] Ministry of Health Republic of Indonesia, Permenkes no 88th 2015 tentang Dewan Pengawas RS, (2015).

[28] Object Management Group, Business Process Model and Notation (BPMN), Object Management Group, Inc., (2011).

[29] A. A. Siyal, A. Z. Junejo, M. Zawish, K. Ahmed, A. Khalil and G. Sourson, "Application of Blockchain technology in Medicine and Healthcare: Challenges and Future Prospective," Journal of MDPI, (2019).

[30] Ministry of Health Republic of Indonesia, Keputusan Menkes no 410th 2016 ttg RS Registrasi Kanker, Ministry of Health Republic of Indonesia, (2016).

[31] Nasef, Eithar Mohamed Mahmoud, and Nur Azaliah. "Enterprise Architecture 'As-Is' Analysis for Competitive Advantage." International Journal of Advanced Computer Science and Applications 11, no. 7 (2020). doi:10.14569/ijacsa.2020.0110714.

[32] H. Lu, W. Wang, H. Wang, D. Wang and J. Yuan, "An Enterprise Architecture Approach to Address Health Interoperability Challenges in the US during COVID-19," Enterprise Architecture Professional Journal, (2020).

[33] Dharmais Cancer Hospital. "Keputusan Dirut no HK 02.02/42/11507/2020 tentang Panduan Manajemen Data RS Kanker Dharmais.” Dharmais Cancer Hospital, Ministry of Health, Republic of Indonesia. (2020).

[34] The Stationary Office (TSO). Information Technology Infrastructure Libray - ITIL v.3 2011 edition. Best Management Practice. (2011). Available online: www.best-management-practice.com (accessed on March 2021).

[35] Setiawan, Awan, and Erwin Yulianto. "E-Government Interoperability and Integration Architecture Modeling Using TOGAF Framework Based On Service Oriented Architecture.” The Asian Journal of Technology Management (AJTM) 11, no. 1 (2018): 26-43. doi:10.12695/ajtm.2018.11.3.

[36] Van den Berg, Martin, Raymond Slot, Marlies van Steenbergen, Peter Faasse, and Hans van Vliet. "How Enterprise Architecture Improves the Quality of IT Investment Decisions." Journal of Systems and Software 152 (June 2019): 134-150. doi:10.1016/j.jss.2019.02.053.

[37] Ajer, Anne Kristin Sortehaug, Eli Hustad, and Polyxeni Vassilakopoulou. "Enterprise Architecture Operationalization and Institutional Pluralism: The Case of the Norwegian Hospital Sector.” Information Systems Journal 31, no. 4 (January 26, 2021): 610-645. doi:10.1111/isj.12324. 